foreshadowing further developments in this field which are planned to take place during the next five years. In addition to a total of thirteen individual research rooms, the laboratory possesses a large workshop, dark rooms for photography and physiology, instrument and balance rooms, a glass-blowing room and a cold room.

Built in spacious Victorian style, the original houses have contributed to the domestic amenities with little modification. The common rooms for staff and technicians are served from a small kitchen, which is available not only to provide coffee and tea for the usual breaks but also for individuals to prepare their own meals-a facility greatly appreciated if working late into the night on material collected on the evening low-water. The rapidly growing library and the reading room occupy the whole of the second floor of one of the houses. Most of the current periodicals in marine biology and oceanography are now taken by the library and a volume of collected reprints covering the fields of taxonomy, ecology, behaviour, physiology and biochemistry is exchanged annually with other laboratories all over the world. The whole building has been decorated throughout in pleasing contemporary style, with the effect of blending the old and new fabric.

\section{MENTAL HEALTH IN THE UNITED STATES}

CEVERAL significant events with far-reaching $\checkmark$ implications for mental health occurred in the United States in 1961. A notable milestone was the publication of Action for Mental Health. This report presents the findings of a six-year study by the Joint Commission on Mental Illness and Health, authorized by Congress in 1955 to evaluate the needs and resources of the mentally ill in the United States and make recommendations for a national mental health programme.

The Commission included representatives of 36 national organizations. Among its findings are: that the demand for public mental health services is still largely not met, in spite of the great gains made during the past decade; probably not more than 20 per cent of the 277 State mental hospitals have participated in innovations designed to make them therapeutic as contrasted with custodial institutions; the average proportion of general State expenditures allocated to mental hospitals has declined in recent years; an average of 4.72 dollars per patient per day is spent by State hospitals, as compared with $31 \cdot 16$ dollars for community general hospitals and 12 dollars or more for Veterans Administration psychiatric hospitals; the persistent attitude that schizophrenia is incurable is false. With proper treatment the schizophrenic has a 3 in 5 chance of leading a useful life in the community; and the rejection of the mentally ill by society has been a major factor in the lag in effective treatment. More helpful attitudes should be created.

The Commission recommends that there is a need for more long-term and basic research in mental illness; in patient care, emphasis should be devoted to breaking down barriers between hospital and community; providing more immediate help and extending care of mental patients through clinics and other agencies; improving the therapeutic milieu in the mental hospital and developing after.
At present there are six teaching staff, four fulltime research staff employed on projects supported by bodies outside the University, and twelve staff employed in technical, secretarial and other capacities. There are eight postgraduate students and, during the first year in which the teaching wing has been used, some ninety undergraduate students from the University of Wales and from elsewhere have received instruction in courses covering marine zoology, algology and physical oceanography and limnology.

No account of the laboratories would be complete without reference to the site itself. The laboratories stand less than fifty yards from the floating stage of the pier to which large and small boats can be moored and from which sea-water can be pumped at all states of tide. The Menai Straits themselves afford safe anchorage within easy access of the Irish Sea. The hitherto unspoiled coasts of Anglesey and Caernarvonshire sustain an exceptionally rich and varied marine fauna and flora. Combined with these practical advantages, the laboratories enjoy a situation of great scenic beauty, having a commanding view of the Menai Straits from the Telford Suspension bridge to the west as far as Beaumaris Bay and the Great Orme to the east.

care programmes; the pace of recruitment and training for all categories of mental health should be accelerated; efforts should be made to increase the use of non-medical mental health workers; more adequate intensive treatment of acutely ill patients is needed; one fully staffed mental health clinic is needed for each 50,000 population; more psychiatrists in private practice should be encouraged to participate in community clinic services; psychiatric units in all community general hospitals with more than 100 beds are desirable; new State hospitals construction should be confined to intensive treatment centres of 1,000 beds or less; and a programme should be eventually developed whereby the Federal Government shares with individual States the cost of mental patient services, over and above present and future programmes of Federal grants-in-aid for research and training.

A special State Governors' conference on 'Mental Health" was held in Chicago during November 1961, to discuss directions and emphases for effective planning for more adequate care and treatment of the mentally ill. At the two-day meeting the Governors expressed their concern for what they described as "the number one health problem of the Nation" by drafting resolutions calling for accelerated action. They commended the Joint Commission for its study and endorsed the concept that Federal, State and local government as well as private and voluntary efforts must be combined to achieve goals sought.

Another event was the publication of the Report of the Surgeon General's Ad Hoc Committee on Planning for Mental Facilities. Its major recommendations include: (1) the establishment of community-based mental health facilities offering a wide spectrum of services, as part of a co-ordinated system of Statewide health services; (2) stimulation of comprehensive planning for mental health facilities by action of the Governors of the State, through designation of an existing agency or appointment of a planning body 
of professional and citizen groups and enactment by the States of enabling legislation to encourage development of needed mental health facilities.

A comprehensive attack on mental retardation was launched in October 1961, with the appointment by President Kennedy of a panel of 27 experts to explore possibilities for its prevention and cure.
The panel will survey biological, psychological and educational, vocational and socio-cultural aspects of mental retardation and their impact on each state of human development. It will determine the adequacy of existing knowledge. Recommendations of the panel will be submitted to the President in December 1962.

\section{TRANSOSONDE STUDIES OF THE ATMOSPHERE}

\section{A} TECHNIQUE which has been evolved in the United States during the past decade to study atmospheric motion by sounding the atmosphere with constant-level balloons has recently attracted considerable attention. J. K. Angell of the U.S. Weather Bureau, at present attached to the Meteorological Office at Bracknell, describes the results of observations which have been collected from such transocean soundings (transosondes) during the past several years in a review article in Advances in Geophysics ${ }^{1}$.

Conventional analyses of meteorological motion on the synoptic scale have been based on data of Eulerian type, that is, data which give the properties and positions of different air parcels at the same time. An alternative method is to base analyses on Lagrangian type data, that is, data which give the properties and positions of the same parcels of air at different times. It is surprising that Lagrangian methods, which have occupied an important place in hydrodynamics, have served so little purpose in meteorology. The use that is being made at present of tracer techniques in general circulation research has renewed interest in the Lagrangian concept. The development of constant-level balloons offers an opportunity of applying quasi-Lagrangian type data to operational and research meteorology.

The constant volume, helium-filled, transosonde balloon is set to drift with the wind at about 250 300 mbars, the level of the jet stream and the lowest level at which the balloons may be flown under the existing U.S. Civil Aeronautics Administration regulations. Its equilibrium floating-level is maintained by means of the release of gas or the dropping of ballast. The balloon carries a transmitter and is tracked by a network of radio direction-finding stations. More recently flights have been made with a new type of balloon, a super-pressured transosonde system which has the capability of maintaining constant-level flight without releasing ballast.

The basic data obtained from transosonde flights are the positions as a function of time. From the differences in these successive positions velocities and accelerations can be determined. The equations of motion of air moving over the surface of the Earth may then be used to deduce a number of parameters among which are the component velocities of the geostrophic and ageostrophic winds, values which are important to basic studies in dynamic and synoptic meteorology. In addition to computing the natural ageostrophic components the zonal and meridional components of the ageostrophic wind may be obtained. The product of these components with each other and with the geostrophic components are associated with the meridional transport of momentum, an important process in the working of the general circulation.
Additional derived parameters which can be obtained from the constant-level balloons are vertical motion, vorticity and divergence. The vertical velocity may be obtained by measuring the change in temperature following the balloon along a constant pressure surface, assuming adiabatic motion. Vorticity may be calculated from the balloon track and the divergence obtained from the usual vorticity equation. Alternatively, divergence can be estimated from the temporal change in triangular area delineated by a triad of balloon flights. Information of the kind mentioned here is supplementary to that which can be found by conventional synoptic methods.

But where transosonde data may help to clarify some of the less understood facets of atmospheric motion is in the identification of oscillations which do not appear in the normal forms of analysis. In particular, inertial oscillations are filtered by the geostrophic assumption which is applied to contour patterns of upper-level air-flow. The inertial oscillation which is contained in the equation of motion has a period of $2 \pi / f$, where $f$ is the Coriolis parameter, a function of latitude and the rotation of the Earth. This is about $18 \mathrm{hr}$. at latitude $40^{\circ}$; at lower latitudes the period is greater and at higher latitudes it is less. The inertial period is reduced if the air parcel moves through a region of cyclonic geostrophic vorticity, and it is increased if the parcel moves through a region of anticyclonic geostrophic vorticity.

Oscillations of inertial character have been found on some individual transosonde flights, but their statistical verification by spectral analysis has not been successful. But this is not surprising when it is realized that the inertial period will vary along each trajectory and for each flight. It is suggested that oscillations of $18 \mathrm{hr}$. or other fixed $2 \pi / f$ period may not show up from trajectory data owing to a systematic variation of wind speed and pressure gradient along wave-shaped trajectories. In any event, it will be necessary to make many balloon flights of longer duration before the problem of the reality of inertial oscillations is settled.

Another little-known characteristic of the upper wind at the level of the jet stream is the so-called abnormal or anomalous flow. Such phenomena are related to regions of dynamic or inertial instability where the total absolute vorticity is negative, that is, where the relative vorticity of the flow exceeds the Coriolis parameter. Trancosonde trajectories have shown striking evidence of such conditions. The ghosts of inertial oscillations and of the strange flow associated with dynamic instability cannot yet be laid.

The transosonde technique shows a change of emphasis which may be needed to make a step forward in the fields of operational and research meteorology. It possesses the advantage that the meteoro- 